\title{
BURRO, MONJE, EUROPA. ANÁLISIS Y TRADUCCIÓN AL ESPAÑOL DEL POEMARIO ËZELIS, MŪKS, EIROPA (1927), DE ANDREJS KURCIJS
}

\author{
EMILIO QUINTANA PAREJA
}

Instituto Cervantes de Estocolmo, Suecia

\begin{abstract}
Resumen. Andrejs Kurcijs (nombre real Andrejs Kuršinskis, Asite, 1884-1959) fue un poeta letón de vanguardia, que tuvo una notable actividad política durante el período de entreguerras. En este artículo, se analiza su relación con España y con la poesía de vanguardia, mediante la traducción al español de su libro Ėzelis, mūks, Eiropa (Burro, monje, Europa). Se compone de 18 poemas escritos durante una estancia en España. En sus memorias inéditas Mana laika grāmata (El libro de mi tiempo), leemos que en el verano de 1927 Kurcijs pasó una temporada en Madrid junto al poeta futurista lituano Juozas Tysliava. De esta forma, fue en Madrid (y en Biarritz) donde se escribieron los poemas de Burro, monje, Europa. Lo que aquí se presenta es la primera traducción al español de la poesía de vanguardia que Kurcijs escribió en España, así como un primer análisis de su contenido poético, hispano, político y vanguardista.
\end{abstract}

Palabras clave: Kurcijs, traducción, vanguardia letona, activismo, ultraísmo

\section{INTRODUCCIÓN}

Este estudio y traducción se enmarcan en un proyecto personal más amplio de traducción de libros de vanguardia que tienen relación con el ultraísmo en español. En esta línea, se han publicado ya mis traducciones de Pierre AlbertBirot, del francés, Poemas cotidianos (Albert-Birot, 2015), y del sueco Henry Parland Liquidación de ideales (Parland, 2014). Ambas traducciones las he hecho en solitario, debido a mi conocimiento de ambas lenguas.

La decisión de traducir al español a Kurcijs se debe al encuentro con la profesora letona Aija Braslina en Estocolmo hace algunos años. Es autora de muchas publicaciones dedicadas a la historia del arte en Letonia, sobre todo en la primera mitad del siglo pasado (Braslina, 2008; 2010; 2011). Fue ella quien dio a conocer la figura de Kurcijs, y me puso sobre la pista de sus vinculaciones con España. Debido al desconocimiento de la lengua letona me puse en contacto con la especialista en arte moderno Ieva Kalnača, que ha resultado el perfecto 
complemento para que este estudio y traducción sean una realidad plena. Su excelente manejo del español junto con mi frecuente lectura y estudio de la poesía ultraísta hispana ha dado lugar a una traducción completa del poemario Burro, monje, Europa, que considero enormemente satisfactoria.

El objetivo, por tanto, de este estudio y de la posterior publicación del poemario completo de Kurcijs es el de dar a conocer al público hispano una de las aportaciones más significativas de la primera vanguardia europea cercana a la dimensión internacional del ultraísmo.

\section{EL AUTOR}

Andrejs Kurcijs (1884-1959) fue el seudónimo del poeta letón Andrejs Kuršinskis, que además fue médico, escritor y político. Participó en los eventos de la Revolución de 1905, que lo llevaron a emigrar a Alemania, donde estudió medicina y filosofía en la Universidad de Jena (1905-1911). Durante la Primera Guerra Mundial, ejerció como médico en la Academia Médica de Guerra de San Petersburgo (1915-1918). Perteneció al Partido de los Socialistas Independientes de Letonia, fue miembro del Consejo Nacional de Letonia (1918-1920), miembro de la Asamblea Constituyente (1921-1922), y diputado (1928-1931).

En 1949, las autoridades de ocupación soviéticas lo detuvieron por motivos políticos y fue deportado al campo de concentración de Komi ASSR (1949-1955). Después de la muerte de Stalin fue liberado y regresó a Riga, donde murió el 23 de febrero de 1959.

En 1923, se hizo conocido por el libro Aktīvā māksla (Arte activo), en el que fundamentaba sus principios vanguardistas bajo el nombre de activismo (Pelše, 2003: 96-104), un ismo con el que rechazaba todo tipo de expresión académica impresionista o naturalista, para enfatizar el papel social/político del arte a través de la creación de emociones puntuales subjetivas.

Burro, monje, Europa (1927) forma parte de su poesía de vanguardia (activista), junto con otros títulos como Barbars Parizēe (1925), publicado en francés en traducción de Helene Izdebska con introducción de Paul Dermée y retrato de Louis Marcoussis: Un barbare à Paris (Kurcijs, [1925] 1928). En el caso del primer libro, se trata de poemas escritos en buena parte en España y que giran sobre temas españoles.

\section{BURRO}

La sensibilidad de Kurcijs hacia los animales se manifiesta a través de referencias y poemas sobre el burro y el toro de lidia. En Burro se conduele ante la suerte de un asno de carga fustigado por su dueño. El burro es sabio, como Rocinante, al que califica de 'grande' en En España (Kurcijs, [1927] 2019, traducción de Quintana Pareja). En cuanto al toro de lidia, En el circo de Madrid queda también reflejado su sufrimiento en las corridas de toros 'para general regocijo' de los 'madrileños' (ibid.). Sin embargo, a diferencia del burro, el toro puede defenderse, 
si bien el público disfruta igualmente de la muerte del torero 'por dos pesetas'. Lo que se dibuja en estos poemas es una sociedad decrépita y cruel, que recuerda los espectáculos de los circos romanos (que es la forma correcta en la que debemos entender la palabra circo en este contexto).

Este acercamiento al mundo natural, al sufrimiento de los animales en el seno de una civilización 'moribunda', se anticipa en buena medida al de Federico García Lorca en Poeta en Nueva York, que recoge poemas escritos entre 1929-1931 fundamentalmente (García Lorca, 1994). En Al Océano Atlántico, Kurcijs se ceba con brillantez en la lujosa decadencia de Míster Grancapital, que 'le saca la piel a tiras al trabajador' con su 'máquina de calcular', al mismo tiempo que expone a las mujeres que lo rodean ('la pedicura hecha / la manicura') con sus 'opulentos ejércitos de cheques' (ibid.).

Todo cálculo y número frío, como en el Lorca neoyorquino, que se conduele con el sacrificio de patos y vacas, y profetiza el fin de un sistema basado en la geometría numérica. Otro elemento que une al poeta letón con Lorca es el simbolismo del agua, que corre como elemento marino que lava, enjuaga, los muelles de Nueva York y las costas decrépitas de Europa.

En todo caso, Kurcijs no descarta los aspectos más futuristas o industriales del comunismo, en la línea de la consigna leninista: 'El comunismo es el poder de los soviets más la electricidad' (Brasliṇa, 2008: 33), de modo que propone, en Jums (Para vosotros), una forma moderna de lanzar el mensaje comunista. Quiere:

descubrir y telegrafiar

a todos

desde la nueva central telefónica

para vosotros

una nueva alegría. (ibid.)

La importancia icónica de Para vosotros se resuelve en su publicación posterior en el primer número de la 'revue internationale' parisina MUBA, Mūsų baro apžvalga eina kas ménuo, que estaba dirigida por Juozas Tysliava (1902-1961), y que publicó dos números (Kurcijs, 1928: 9). En MUBA Revue Internationale el poema iba ilustrado con una reproducción de Ave Maria, cuadro de R[omans] Suta (1896-1944), una naturaleza muerta cubista en forma de collage en el que aparecen un periódico, un balcón, una farola, un puñal, algunos edificios modernos de inspiración italiana, y una pizarra con el Ave María del tenor italiano Caruzo [sic] (Suta, 1995).

Es importante destacar que Romans Suta (1896-1944) fue un pintor, artista gráfico y teórico del arte letón, representante de las ideas cubistas y constructivistas en Letonia, formaba parte del Grupo Expresionista letón (1919, desde 1920 se llama Grupo artístico de Riga) y la sociedad artística Zaḷa Vārna (desde 1926). El pintó fundamentalmente naturalezas muertas y composiciones figurativas (ibid.). El cuadro que acompaña el poema Para vosotros de Kurcijs en $M U B A$ es un magnífico ejemplo de su obra. 
En estos días puede considerarse otro poema en esta línea eléctricamente leninista (Kurcijs, [1927] 2019).

\section{MONJE}

Kurcijs se siente atraído por el arte español, en especial por la obra de El Greco, pero también por Zurbarán y Ribera. En cierto modo, su admiración por el genio español se centra en la palabra monje, que hace referencia -por la descripción poética- al San Antonio de Padua del cretense (c. 1580. Óleo sobre lienzo, $104 \times 79 \mathrm{~cm}$.), que pudo ver repetidamente en el Museo del Prado.

Sin embargo, a pesar de su admiración por el sagrado fervor de los monjes de la pintura española del siglo XVII, el poeta letón manifiesta con crudeza su anticlericalismo mediante una brusca transición a 1927. El monje de El Greco está vivo, pero ahora...

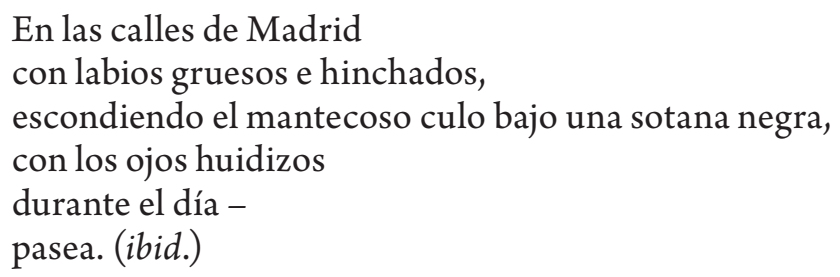

Desde un punto de vista político, Kurcijs pone el foco sobre la figura del general Primo de Rivera (1870-1930), que en 1927 era el jefe del directorio que gobernaba sobre 'la moribunda tierra de España'. A Primo de Rivera le dedica el poema Espía, en el que lo degrada con giros humorísticos y juegos de palabras (lo llama 'el primo ciudadano', que en español conlleva una afortunada segunda acepción, que enriquece involuntariamente nuestra traducción, ya que 'ser un primo' es 'ser un imbécil'), del que destaca su 'burricie', lo que lo pone en las antípodas del 'sabio' burro de poemas anteriores (ibid.).

Por lo demás, hay otro aspecto de España que Kurcijs incluye en sus versos, en referencia al mundo de la alta sociedad que, en esta época, se daba cita en la costa vasca entre Biarritz y San Sebastián, ciudad de veraneo de la aristocracia hispana. Léanse para ello poemas como Al Océano Atlántico o La sed masculina (Kurcijs, [1927] 2019).

\section{EUROPA}

Kurcijs defiende el comunismo como remedio a la podredumbre de Europa. En Tarde europea afirma el crepúsculo de una civilización que, a su entender, sólo puede ser redimida por las 'ideas nuevas'. En Después de la victoria (ibid.) por ejemplo, se hace un canto a la Comuna de París, para cerrar con estos dos versos: 'Asesinado el espíritu / se pudre Europa'. Estamos ante una Europa que bosteza ('sobre el aburrimiento de la vieja Europa') (ibid.). Si bien la etimología de aburrimiento no tiene relación con la palabra burro, nos encontramos de nuevo 
con otro 'seguro azar'. Seguro azar es el título de uno de los libros de vanguardia del poeta español Pedro Salinas, publicado en 1929 que enriquece la traducción (Salinas, 1929).

Sin embargo, el concepto de Europa como ámbito decadente aparece especialmente circunscrito al mundo anglosajón: 'Vosotros / ingleses, / norteamericanos, / ciudadanos del mundo entero, con dinero bastante y moneda en la Bolsa', (en Anuncio en el escaparate de una farmacia europea). La sed masculina es un vitriólico retrato del 'yanqui adinerado' que viene a Europa para gastar sus dólares, y concluye: 'El nuevo continente se hace viejo' (Kurcijs, [1927] 2019).

Hay que destacar que la vanguardia de Kurcijs tiene mucho más que ver por sus referentes políticos con la de algunos poetas de la zona báltica como el finés Elmer Diktonius (1896-1961) que con la de Henry Parland (1908-1930), poeta sueco-finés de origen ruso, más cercano al cubismo poético. La poesía de Parland es un canto a la 'liquidación de ideales' de la modernidad lleno de inteligencia y espíritu burlón. En Liquidación de ideales, los anuncios y el mundo del comercio son vistos de un modo irónico pero positivo:

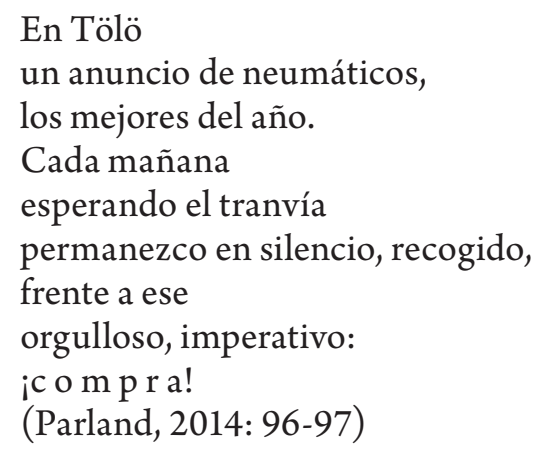

En el caso de Kurcijs, sin embargo, la publicidad es parte de la podredumbre escatológica del mundo capitalista. Así comienza su Anuncio en el escaparate de una farmacia europea:

La mejor agua mineral

contra el estreñimiento y todas las enfermedades

para los que

habéis comido en exceso y estáis llevando

la cruz del entrecot

con penitencia y sudor frío.

(Kurcijs, [1927] 2019)

Por lo demás, no falta en Kurcijs el apunte de actualidad, en forma de poema dedicado a la ejecución de los anarquistas Sacco y Vanzetti. En este caso, el poeta letón une de nuevo el eslogan leninista que relaciona política y electricidad en un modo transgresor, ya que concibe la silla eléctrica como una fuente de energía para el corazón de los ejecutados y su causa. Este voltaje, afirma, 'destruirá los 
países del viejo mundo' (En memoria de Sacco y Vanzetti), es decir, el decadente sistema capitalista (ibid.).

La estructura del libro está muy bien pensada. Si el poema que lo abre se puede considerar una declaración de intenciones, el penúltimo es una petición de respuesta dirigida al gran descubrimiento español de Kurcijs: El Greco. Al dirigirse a él, sin embargo, concluye que la respuesta no puede venir del pasado sino de la lucha presente. Leemos en El Greco en un museo de Madrid:

Pero guardas silencio,

te has ido de esta tierra,

estás callado.

Ahora lo sé:

Sólo queda la lucha hasta el final,

y los que,

nos sucedan. (ibid.)

\section{CONCLUSIONES}

En definitiva, Burro, monje, Europa es un libro plenamente inmerso en la primera vanguardia internacionalista europea, muy cercano a la obra de autores como el sueco-finés Elmer Diktonius.

Uno de los aspectos más destacables desde el punto de vista hispano es la forma en que ilumina una obra como Poeta en Nueva York, de Federico García Lorca, heredero directo del movimiento ultraísta madrileño en su vertiente creacionista. Si consideramos que la dictadura de Primo de Rivera (1923-1930) supone un paréntesis creativo entre el fin del movimiento ultraísta y el nuevo ambiente cultural de la II República Española, resulta notable la visión poética de ese espacio sociocultural por parte de autores extranjeros como Kurcijs, que visitan España y captan con sutileza y magistral forma artística el ambiente. De este modo, lo que se ha venido en llamar vanguardia casticista puede ser reinterpretada dentro de un espectro más amplio gracias a poetas como Kurcijs, que fija su mirada en una España ensimismada, de modo similar a la forma en que Lorca lo hará ante un Nueva York babilónico. A pesar de su carácter explícitamente político, el libro es una encrucijada de aciertos poéticos: modernidad y tradición, casticismo e internacionalismo, realismo y esperpento, barbarie y civilización, decadencia (Spengler, 1923: 23) y hombre nuevo, sajones y latinos, masculinidad y feminismo, El Greco y Joselito, campo y urbe...

Estamos, por tanto, ante un libro de una riqueza inagotable.

\section{REFERENCIAS BIBLIOGRÁFICAS}

Braslina, A. (2008) Encounters of Latvian Modernists with Secondo Futurismo in the 1920s. Mākslas Vēsture un Teorija, (10): 32-45.

Brasliņa, A. (2010) Latvia. En Günter Berghaus (ed.) Handbook of International Futurism (pp. 656-668). Berlín, Boston: De Gruyter. 
Braslina, A. (2011) Latvian Modernists in Berlin and Rome in the 1920s: Encounters with secondo futurismo. International Yearbook of Futurism Studies, (1): 231-261.

Pelše, S. (2003) Active Art (Aktīvā māksla) by Andrejs Kurcijs. En K. Ābele (ed.) Latvijas māksla tuvplānos (pp. 96-104). Rīga: Neputns.

Pelše, S. (2003b) Latviešu futūrists un tradīciju noliedzējs Niklāvs Strunke - jaunatklātās teorētisko uzskatu liecības (Latvian Futurist and anti-Traditionalist Niklāvs Strunke - newly discovered theoretical statements). En I. Daukste-Silasproge (ed.) Materiāli par latviešu un cittautu kultūru Latvijā (pp. 101-109). Rìga: Zinātne.

Parland, H. (2014) Liquidación de ideales. (Traducción de E. Quintana Pareja). Granada: El Genio Maligno.

Salinas, P. (1929) Seguro azar. Madrid: Revista de Occidente.

Spengler, O. (1923) La decadencia de Occidente. Madrid: Espasa-Calpe.

Suta, T. (1995) Romans Suta. Riga: Liesma.

\title{
RECURSOS DE ANÁLISIS EMPÍRICO
}

García Lorca, F. (1994) Poeta en Nueva York. M. C. Millán, (ed.). Madrid: Cátedra.

Kurcijs, A. (1928) Jums. En J. Tysliava (ed.) MUBA. Revue Internationale, (1): 9. Paris: [s.n.].

Kurcijs, A. (1927) Ēzelis, mūks, Eiropa. Rīga: Neatkarīgais vārds.

Kurcijs, A. ([1927] 2019) Burro, Monje, Europa. Poemas en traducción del letón a cargo de Emilio Quintana Pareja e Ieva Kalnača. Disponible en http://www.emilioquintana.com/ avantgardenetwork/ultraismos-europeos/burro-monje-europa-1927-de-andrejs-kurcijsleton/ [Consultado el 28 de junio de 2019].

Kurcijs, A. (1925) Barbars Parizēe. Rīga: Laikmeta Izdevums.

Kurcijs, A. ([1925] 1928) Un barbare à Paris. (Traducción al francés de Helene Izdebska). Paris: Editions des D. I. de l'esprit nouveau.

Parland, H. (2014) Liquidación de ideales. (Traducido del sueco por E. Quintana Pareja). Granada: El Genio Maligno.

Albert-Birot, P. (2015) Poemas cotidianos. (Traducido del francés por E. Quintana Pareja). Sevilla: Renacimiento.

\section{DONKEY, MONK, EUROPE. ANALYSIS AND TRANSLATION INTO SPANISH OF ËZELIS, MŪKS, EIROPA (1927) BY ANDREJS KURCIJS}

\begin{abstract}
Andrejs Kurcijs (real name Andrejs Kuršinskis, Asite, 1884-1959) was a leading Latvian poet, who showed notable political activity during the interwar period. In this paper, his relationship with Spain and avant-garde poetry is analyzed through the translation into Spanish of his book Ezelis, müks, Eiropa (Donkey, Monk, Europe). Donkey, Monk, Europe is composed of 18 poems written during his stay in Spain. In his unpublished memoirs Mana laika grāmata (The book of my time), we read that in the summer of 1927 Kurcijs spent a season in Madrid with the Lithuanian futurist poet Juozas Tysliava. Thus, it was in Madrid (and in Biarritz) where the poems of Donkey, Monk, Europe were written. What is presented here is the first Spanish translation of the avant-garde poetry that Kurcijs wrote in Spain, as well as the first analysis of its poetic, Hispanic, political and avant-garde content.
\end{abstract}

Keywords: Kurcijs, translation, Latvian avant-garde, Activism, Ultraism 


\section{ANEJO 1}

\section{Poemas de A. Kurcijs y su traducción al español}

Apnicis dzejot par ziedonīti, par to, ka atausīs rīti, par dvēseles zaigu un maigu un visu to muḷ, kỉbu liktenīgo, sakrauto klasiskā pantā diezgan!

Diezgan glēevuma traipiem aptašķì slejas!

Labāk ir dūšu saṇemt un klusēt, iziet ielās un nostāties cūcības triumfam ceḷā ar paceltu roku:

Diezgan!

\section{$\bar{E} z e l i s$}

Mazām kājiṇām kā Ķinas dāmai, apkrauts sainiem, redz tik

lielās ausis, pelēks ēzels kraujāi ielā kāp, saṇemdams ik minūti ar stibu neapkrautā vietā.

Ėzelis ir arī prātnieks:

Domā viņš par ciešanām kā Stoa,

Acīs viñam

$$
\begin{aligned}
& \text { mūžīgs } \\
& \text { drūmīgs } \\
& \text { klusums. }
\end{aligned}
$$

Tomēr neiztur pat prātnieks:

kalnā uzrāpies, tas atskatās uz bendi, kas to modri pavada ar stibu, apstājas Ielā atskan bḷāviens, kuru dzirdot mokās nodreb sirdis.
Ya me cansa escribir versos sobre la floración sobre los amaneceres que están por venir sobre el brillo y la tersura del alma y toda esa fatal estupidez, ordenada en verso clásico ¡Basta! ¡Basta de ensuciarse la cara con manchas de cobardía! Es mejor ser valientes y guardar silencio, tomar las calles y ponerse en pie camino del triunfo de la necedad con el brazo levantado: ¡Basta!

\section{Burro}

Con sus patas pequeñas como una dama china, cargado de alforjas, mostrando apenas sus grandes orejas, un burro gris, por una empinada cuesta sube, fustigado a cada instante - hasta donde la fusta alcanza.

El burro es también sabio: medita sobre el dolor como un estoico, hay en sus ojos

$$
\begin{gathered}
\text { un eterno } \\
\text { sombrío } \\
\text { silencio. }
\end{gathered}
$$

Pero hasta un sabio tiene un límite: subida la cuesta, contempla a su verdugo, que atentamente lo sigue con la fusta, se para resuena un grito en la calle, al oírlo el corazón tiembla sufre. 
Mūks

\section{Rokā}

ar lilijas balto ziedu,

kas klusi

izstīdz no slaidiem pirkstiem,

svētu kvēlu liesajā sejā,

sāpēm uz lūpām -

Elgreko mūks.

Bet miris Elgreko,

Zubarans miris - Ribeira;

tik vienmēr

vēl vienmēr -

dzìvs mūks.

Madrides ielās

tuklām galīgām lūpām,

melnā svārkā trekno pakaļu slēpdams,

viltīgām acīm

dienā viņš -

staigā.

Vakarā

zvana no lepniem torņiem

savu pestī̌sanu -

visiem mulkiem.

\section{Eiropisks vakars}

Saule iegāžas Atlantikā

plata,

kvēlošām miesām

un aizpeld uz Ameriku.

Un augstās villas augstā krastā

nodziest,

pelēki skumst

par vecās Eiropas garlaicību.

\section{Jums}

Neesmu Petrarka.

Avinjonā

pēc pirkstiem nekārtoju četripadsmit rindas

kā nākas sonetās.

Es Laurai nedziedu par godu,

\section{Monje}

En la mano

un lirio blanco,

que florece en silencio

entre sus finos dedos,

un sagrado fervor en el alargado rostro,

y dolor en los labios -

Un monje del Greco.

Pero está muerto El Greco,

Zurbarán está muerto - y Ribera;

y aún así

incluso así -

el monje está vivo.

En las calles de Madrid

con labios gruesos e hinchados

escondiendo el mantecoso culo bajo una sotana

negra,

con los ojos huidizos

durante el día -

pasea.

Por la noche

hace sonar campanas desde torres altivas

para su salvación -

y para todos los memos.

\section{Tarde europea}

El sol se hunde en el inmenso

Atlántico,

con el cuerpo resplandeciente

y nada hacia América.

$Y$ en una alta villa en una alta costa

se extingue,

se entristece de color gris

sobre el aburrimiento de la vieja Europa.

\section{Para vosotros}

No soy Petrarca.

En Aviñón

no ordeno catorce líneas con los dedos

como se debe en los sonetos.

No canto en honor de Laura, 
ar zīdu nešuvu un dārgakmeņiem;

vārdu pērles

neveru kā ubags uz diedziņa,

lai uzliktu tai kaklā.

Kā mūks

vairs dzeju neskaitu kā tēvareizi.

Ne pielūgt gribas man -

Es gribu zināt,

līdz sirdij iespiesties,

pa asins vadiem

ar zemūdenēm izpeldēt līdz galam,

un izpētīt un telegrafēt

visiem

no jaunās centrales

jums

jaunu prieku. no coso con seda y piedras preciosas;

perlas de palabras

ni las ensarto como un vagabundo en un hilo, para ponérselas al cuello.

Como si fuera un monje

no recito la poesía como una oración

No quiero adorar -

Quiero saber,

penetrar hasta el corazón,

a través de los vasos sanguíneos

navegar hasta el final en submarino,

descubrir y telegrafiar

a todos

desde la nueva central telefónica

para vosotros

una nueva alegría.

Emilio Quintana Pareja (Dr. en Filología Hispánica por la Universidad de Granada, España). Ha sido profesor en las Universidades de Granada (España), Lund (Suecia) y Pavía (Italia). Ha sido profesor de plantilla del Instituto Cervantes de Utrecht (Países Bajos), y actualmente es Coordinador Académico del Instituto Cervantes de Estocolmo (Suecia). Su campo de investigación fundamental son los estudios literarios y culturales, en especial las relaciones entre las vanguardias europeas durante la primera mitad del siglo XX. Correo electrónico: equintan@gmail.com 